Al mismo tiempo, el retrato evoca toda una historia de resentimientos y satisfacciones. Los datos de los documentos, aun siendo tan sobrios, reflejan la situación de los tres actores envueltos: comprendemos el drama de Don Carlos en su afán desmesurado de multiplicar y distribuir una imagen suya favorable, intuimos la resignación del pintor de cámara, que, para sobrevivir en la corte, tuvo que copiar, o dejar copiar, hasta la saciedad un retrato diametralmente opuesto a su propia interpretación del Príncipe, y finalmente notamos el éxito rotundo de la dama Sofonisba, con la seguridad que le daba su posición en la corte, con su concepto de belleza italiano, unido a su sensibilidad femenina que, siguiendo al mismo tiempo su propia naturaleza y el carácter de su encargo, supo transformar, de una forma creíble para su entorno, al Príncipe en el joven normal y robusto que hubiese querido ser y que su padre hubiese deseado que fuese.

María KusChe

\title{
EL DOCUMENTO PINTADO EN LA BAJA EDAD MEDIA ESPAÑOLA. COMENTARIOS Y ADICIONES A UNA EXPOSICIÓN RECIENTE
}

Este escrito pretende aportar reflexiones y nuevas propuestas a la exposición denominada El documento pintado ${ }^{1}$ que ha sido inaugurada recientemente en el Museo del Prado. La mera existencia de una exposición dedicada a manuscritos iluminados merece una felicitación pues indica un nuevo interés por parte del museo a un muy importante ámbito de la pintura europea determinado por un tipo de coleccionismo que se modificó radicalmente en el siglo xviI. «Mientras que los manuscritos con pinturas de la Edad Media y del siglo xvi formaban parte de las cámaras del tesoro («Wunderkammern») de príncipes, magnates y eclesiásticos, donde eran únicamente accesibles al poseedor y a su círculo más próximo, desde el siglo XVII surgen las galerías de pinturas, en las que los códices iluminados ya no tenían lugar» ${ }^{2}$.

A pesar de esta nueva actitud ante la pintura en manuscritos que manifiesta su exposición en el Prado, uno de los estudios del catálogo deja traslucir una valoración —aunque con un matiz dubitativo- de las obras expuestas en la que los manuscritos iluminados son considerados como pinturas de segunda categoría: «el análisis de estos documentos ha de permitirnos seguir el camino que va desde las formas de creación consideradas tradicionalmente superiores hasta unas formas quizá menores artísticamente pero de indudable valor estético y de no menor valor icónico en el contexto de una sociedad eminentemente simbólica» ${ }^{3}$.

Esta valoración parece desconocer un hecho plenamente asentado en la historiografía artística actual: la idea de que si bien, en ocasiones, la miniatura es un arte menor, simple reflejo, y a veces muy alejado, de la «gran pintura», como podría ser el caso de las Ejecutorias del siglo $\mathrm{XVII}^{4}$, no sucede lo mismo en algunas épocas de la Edad Media. Desde que en 1953 Erwin Pa-

\footnotetext{
1 Para el contenido de la exposición véase el catálogo de la misma: El documento pintado. Cinco siglos de arte en manuscritos, ed. Ministerio de Educación y Cultura, Museo Nacional del Prado y Afeda, Madrid, 2000, siendo comisarios de la exposición Javier Docampo, Carmen Espinosa y Elisa Ruiz. Estos y otros autores se ocupan de los diversos capítulos del texto aunque en la introducción no se indica quienes son los responsables de las obras seleccionadas de cada periodo.

${ }^{2}$ Cita tomada de A. Domínguez Rodríguez y F. J. Docampo Capilla, Diminuto Devocionario del Museo Arqueológico Nacional. Estudio del códice y sus miniaturas, ed. Grial, s. 1. , 1995, p. 15, volumen complementario de la edición facsímil de dicho manuscrito. Sobre este tema véase J. von Schlosser, Raccolte d'arte e di meraviglie del tardo Rinascimento, Firenze, ed. original de 1908, 1974, p. 12 y M. MORÁN y F. CHECA, El coleccionismo en España, Madrid, 1985, p. 63.

3 J. M. Matilla, «Símbolos de privilegio y objetos de arte. Los documentos pintados en la sociedad española del antiguo régimen» en El documento pintado. . , , p. 21.

${ }^{4}$ La valoración negativa de las Ejecutorias que hago aquí es excesivamente simplista pero intenta contraponer la diferencia acusada entre los grandes miniaturista medievales y del siglo XVI frente a la obra del siglo XVII. El estudio de F. J.
} 
nofsky publicó su famoso estudio sobre la pintura de los primitivos flamencos quedó practicamente asentada la idea de que la personalidad nórdica de la pintura flamenca, manifestada en toda su plenitud en Juan Van Eyck y contrapuesta a la pintura del Quattrocento, debería sus esencias a una evolución manifestada en la miniatura parisina desde la obra de Jean Pucelle a la de los hermanos Limbourgs, entre los años 1320 y 1420. París sería el crisol al que acudirían durante todo este periodo una serie de iluminadores, desde Italia y desde los Países Bajos, atraídos por el poderoso mecenazgo de unos príncipes y soberanos entre los que el duque de Berry es el más conocido ${ }^{5}$. Esta miniatura parisina de la centuria referida constituye, en paralelo con la pintura italiana, la vanguardia de su tiempo y su culminación llegaría en los años 1400 .

Cuando se establecen estas valoraciones y jerarquías entre la miniatura y la pintura del siglo XVII no se recuerdan otros aspectos, tradicionalmente estudiados en el arte español, como puede ser la arquitectura barroca madrileña, que, si bien es analizada con gran denuedo y aceptación, está claramente asumido, incluso por sus más ardientes defensores, que tiene un valor diríamos de arte menor en el contexto del Barroco europeo. Sin embargo, y cada vez más, las obras de arte se estudian, no sólo por sus valores formales y categorías estéticas, sino dentro de un amplio contexto, en el que forman parte de la historia de las mentalidades y de la cultura y en el que se tienen en cuenta tanto la obra de los grandes genios creadores como también otros aspectos de la creación artística.

En relación con el título de la exposición, que ha sido retomado por mi en este breve estudio, conviene, sin embargo, mencionar que toda obra de arte es un monumento, por sus valores estéticos, pero constituye, además, un documento (vid. E. Panofsky, El significado de las artes visuales, Barcelona, 1970, p. 22: se refiere a «aquellos documentos que nos han llegado en forma de obras de arte») de su propia circunstancia histórica. Pensemos, sin ir más lejos, en el Guernica de Picasso que, por su valor de documento histórico de la guerra civil, tuvo que ser blindado a su vuelta a España para poder ser expuesto con seguridad en un museo. En esta exposición la expresión documento pintado no se delimita claramente, al menos en la introducción al catálogo ${ }^{6}$ pero por el contenido de la misma parece referirse a un tipo de formato en el que, además de obras de un sólo folio o de un cuadernillo, hay lugar para códices breves (el Ceremonial de la Consagración y Coronación de los reyes y reinas de Aragón posee treinta y nueve folios ${ }^{7}$ ), y a un tipo de textos de carácter más bien jurídico.

DocAmpo, que acompaña al catálogo de la exposición («Arte para una sociedad estamental: la iluminación de documentos en la España de los Austria», pp. 45-86), va a ser, en mi opinión, la obra básica de referencia para un futuro estudio más amplio de las pinturas de las Ejecutorias. Pensemos, sin embargo, en la gran fama que tuvieron todavía en el siglo xvi iluminadores como Simon Bening y Giulio Clovio y en la importancia que tuvo, sin duda, en el mecenazgo de Felipe II la colección de manuscritos iluminados heredados de sus antepasados y la iluminación de toda una serie de códices por él patrocinada. Sobre la miniatura del Renacimiento vid. A. Domínguez Rodríguez y F. J. Docampo Capilla, op. cit. supra., pp. 11-30, en donde se mencionan, además, las grandes exposiciones dedicadas, en gran parte, a la miniatura europea del Renacimiento y celebradas en los años finales de este siglo en New York (1982), Londres (1984), Écouen (1993) y París (1993). Evidentemente en España falta por hacer el estudio que merece la miniatura patrocinada por muchos monarcas castellanos bajomedievales y renacentistas desde Alfonso XI a Felipe II, aunque existen primeras aproximaciones meritorias que deben sin duda ser tenidas en cuenta.

5 Vid. E. PANOFSKy, Early Netherlandish Painting. Its Origins and character, Icon ed., New York, etc. ., 1971 dedica los capítulos I y II (pp. 21-74 del vol. I) a esta miniatura parisina y las ilustraciones 1-98 (del vol. II). La edición española (E. PAnofsky, Los Primitivos flamencos, ed. Cátedra, Madrid, 1998) prescindió de toda la ilustración gráfica referida a la miniatura y las 496 ilustraciones del libro de Panofsky en su versión original se redujeron a 174 aunque este hecho, tan significativo, ni siquiera se menciona. Ello deja traslucir, junto a una falta de respeto por la obra de Panofsky, un desconocimiento del significado que los estudios de miniatura tuvieron en este historiador. Tampoco se explican las razones por las que se cambió, en la edición española, el título original que precisamente matizaba sobre el planteamiento del libro.

${ }^{6}$ Llamo Introducción al corto texto, sin título, en que S. SAAVEDRA (pp. 11-12) presenta los textos científicos del catálogo que vienen a continuación (pp. 15-98). Aunque no define claramente el contenido de la exposición habla de «títulos de nobleza, ejecutorias y privilegios rodados» sin mencionar las otras obras expuestas que no responden a ninguno de estos apartados.

7 Vid. El documento pintado..., p. 105. 
Como punto de partida a los comentarios más concretos que voy a exponer en relación con las obras góticas y la exposición, he de señalar que siendo su argumento el «documento pintado» todas las obras en ella expuestas deberían poseer valores pictóricos. Pero no existe pintura, sin embargo, en la mayoría de los documentos rodados expuestos en el Museo del Prado aunque poseen, sin duda, un gran valor histórico, diplomático, sigilográfico y paleográfico, que los convierte en objeto de coleccionismo ${ }^{8}$. En nuestra civilización occidental, a diferencia de las del Extremo Oriente y el Islam, la caligrafía no ha sido revestida, al menos en la Edad Media, de valores pictóricos.

Voy a mencionar a continuación documentos pintados del gótico castellano que constituyen ejemplos muy significativos dentro de la historia de la pintura medieval, y que en su mayoría son ampliamente conocidas desde los estudios de Domínguez Bordona, pero que, sin embargo, no han sido tenidos en cuenta en esta exposición ni, en la mayor parte de los casos, tampoco en el texto del catálogo. A ellos voy a añadir otros datos procedentes también de la bibliografía histórico-artística, que se supone debe ser manejada en cualquier exposición de pintura, sea monumental, de caballete o en manuscrito ${ }^{9}$.

El documento pintado con valores artísticos de la Edad Media castellana es escaso en número pues, solamente en muy contadas ocasiones, es merecedor de estos calificativos bien por razones pictóricas o iconográficas ${ }^{10}$. En la exposición se han olvidado sin duda algunos de los ejemplos más eximios y además los manuscritos pintados deberían haber sido analizados desde las diversas disciplinas que se ocupan de los mismos con el fin de aunar las diversas tradiciones historiográficas y de no restar posibilidades a la interpretación de las obras expuestas ${ }^{11}$.

Creo oportuno destacar en primer lugar tres obras bastante representativas de la pintura castellana del siglo xIII, que han sido omitidas en la exposición a pesar de presentar todas ellas retratos regios en sus frontispicios y de ser este tipo de iconografía una de las metas de esta exposición ${ }^{12}$. Las dos primeras, el Tumbo Menor de Castilla ${ }^{13}$ y el Cartulario de Tojos Outos ${ }^{14}$, poseen un carácter claramente jurídico, aunque no me consta la cantidad de sus páginas que pudo ser un obstáculo para llevarlos a la exposición. Tampoco se expuso en el Prado

\footnotetext{
8 Únicamente desde la Diplomática, la Paleografía, la Sigilografía y la Historia Medieval pueden ser valorados los privilegios rodados que aparecen en el catálogo con los números 1, 2, 4 y 5 . Los que aparecen con los números $6,7,8,10$ y 11 tienen valores pictóricos secundarios ya que poseen únicamente orlas con decoración vegetal que desde el punto de vista de la pintura únicamente servirían para ser comparados con otros manuscritos iluminados castellanos con decoración historiada, de época de Juan II y Enrique IV, con el fin de buscar posibles talleres de iluminación. Vid. El documento pintado..., pp. 100- 128 .

9 El estudio de los manuscritos iluminados, y aún más si se incluyen junto a los códices de las bibliotecas los documentos de los archivos, requiere un acercamiento desde diversas dsciplinas y por tanto el manejo de una bibliografía igualmente interdisciplinar, algo muy difícil que se puede suplir con la colaboración de estudiosos de diferentes campos.

${ }^{10}$ Los valores iconográficos de los documentos expuestos son manifestados por E. Ruiz quien considera un retrato de Juan II (en una carta de privilegio del año 1447de la Biblioteca Francisco Zabálburu, M 11-163) como «un temprano eslabón de una tradición bien establecida e ininterrumpida, como lo demuestra la galería de efigies reales que proliferan en la presente Exposición»( «Claves del documento artístico bajomedieval en Castilla» en El documento pintado, op. cit., p. 122).

${ }^{11}$ Esta idea es defendida teóricamente por E. Ruiz («Claves del documento artístico bajomedieval en Castilla», op. cit. supra, p. 42): «La renovación de la metodología historiográfica en estas últimas décadas ha aportado, entre otros beneficios, una superación de los caminos trillados y una ampliación de los campos de observación. No sólo la diplomática se ha abierto a otras piezas de archivo, sino que también la documentación tradicional es examinada desde otros ángulos. Hoy sabemos que el documento no proporciona un testimonio unívoco. Todos los elementos adyacentes al texto escrito son consustanciales».

${ }^{12}$ En la Bibliografía de Elisa Ruiz se citan los trabajos de Collar de Cáceres y Nieto Soria, esenciales para algunos aspectos de la iconografía de los reyes de Castilla y León, aunque se olvida mencionar numerosas aportaciones de valor considerable para este tipo de estudios (E. Ruiz García, «Claves del documento artístico bajomedieval en Castilla» en $E l$ documento pintado, op. cit., p. 43). Vid. una exposición de esa extensa bibliografía multidisciplinar en A. Domínguez RoDRÍGUEZ, «Retratos de Alfonso X en sus manuscritos» en V.V.A.A., Alfonso X el Sabio, impulsor del arte, la cultura y el humanismo. El arpa en la Edad Media española, Madrid, 1998, pp. 95-107.

13 Vid. J. Domínguez Bordona, Manuscritos con pinturas, Madrid, 1933, vol. I, n 396 y fig. 209,

${ }^{14}$ Ibidem, n³95 e il. 208.
} 
el Documento rodado de Sancho IV que, excepcionalmente en este tipo de manuscritos, posee una gran miniatura en la que vemos representada las cinco naves de la catedral de Toledo con un sepulcro en la central. Se trata del documento, firmado solemnemente por Sancho IV y diversos obispos castellanos, en el que el monarca se compromete a ser enterrado en dicha catedral. En la representación, en sección, del alzado del edificio con sus cinco naves, aparecen representados, en las extremas, el rey entronizado y el arzobispo de Toledo, pues son los principales pactantes (fig. 1). Este último documento ha sido aludido en el catálogo por sus valores diplomáticos aunque no en relación con la pintura postalfonsí, en la que se encuadra, ni con el enterramiento regio en la catedral de Toledo ${ }^{15}$. Estos tres manuscritos están en el Archivo Histórico Nacional y, además de poseer valores pictóricos e iconográficos considerables, son documentos de gran importancia para la historia de España.

Resulta completamente inexplicable la ausencia en la exposición de las dos versiones manuscritas iluminadas del Ordenamiento de Alcalá (Biblioteca Nacional, ms. Res 9 y Escorial ms. Z. III. 9. ), que, si bien son códices, poseen más o menos el mismo número de folios que el Ceremonial de Coronación y Consagración de los Reyes de Aragón que aparece en una de las vitrinas. En 1348, poco antes de la muerte de Alfonso XI, fue emitido este ordenamiento que constituyó el remate a la labor de este rey encaminada desde los comienzos a unir a los súbditos por un conjunto de instituciones generales que sirvieran de base jurídica para dicha unión. Buscaba simplemente la monarquía contractual, reinar apoyándose en las Cortes en las que el Estado llano era el elemento esencial. Por ello tuvo que luchar contra la nobleza, a cuyo frente se situaba el infante don Juan Manuel y que había sido alentada, en su rebeldía, por las largas minoridades de Fernando IV y Alfonso XI en las que estuvo al frente del estado la reina Doña María de Molina, esposa de Sancho IV.

Los dos ejemplares iluminados muestran en la belleza de sus miniaturas la importancia del hecho histórico a conmemorar y, además, constituyen un argumento a favor de la existencia de un sólo «scriptorium» regio en el que se escribieran e iluminaran tanto documentos de tipo jurídico y cancilleresco como obras literarias. Pues en ambos códices, como es ampliamente sabido, se encuentra la firma de Nicolás González ${ }^{16}$ cuyo nombre aparece también mencionado en el colofón de la Crónica Troyana ${ }^{17}$. Bertaux y, posteriormente, Camón Aznar relacionaron hace años a este manuscrito con las famosas pinturas de la Sala de los Reyes de la Alhambra de Granada ${ }^{18}$ con lo que el alcance pictórico de las dos copias del Ordenamiento de Alcalá queda notablemente ampliado.

El Ordenamiento de Alcalá de la Biblioteca Nacional tiene, como única decoración pictórica, una sola miniatura que ocupa el sector superior de la primera columna del texto (f. 1) y

\footnotetext{
15 Domínguez Bordona, ibidem, n. 399 y fig. 210; A. Domínguez Rodríguez, «Retratos de Alfonso X en sus manuscritos», op. cit. ; eadem, «El testamento de Alfonso X y la catedral de Toledo», Reales Sitios, 82 (1984) 73-75; eadem, «El Officium Salomonis de Carlos V en El Escorial. Alfonso X y el planeta sol. Absolutismo monárquico y hermetismo», Reales Sitios, 83 (1985) 11-28; F. Gutıérrez BAÑos, Las empresas artísticas de Sancho IV el Bravo, ed. Junta de Castilla y León, 1997, 209-214. En El documento pintado, op. cit., E. Ruız habla de una manera genérica de los privilegios rodados de Sancho IV, incluyendo una fotografía del manuscrito que nos ocupa (p. 38 y fig. 15) aunque no analiza la imagen en concreto.

${ }^{16}$ En el ms. Res 9 de la Biblioteca Nacional, f. XLIv., se lee «Nicolás González lo escribió» y en el escurialense Z. III. 9. f. 60, «Yo Nicolás González, escribano del rey, lo escrivi».

17 En el f. 183 de la Crónica Troyana (Escorial, ms. h. I. 6. ) se lee; «Este libro mandó hacer el muy alto y muy noble y muy excelente rey don ALfonso... E fue acabado de escribir y de estoriar en el tiempo que el muy noble rey don Pedro su fijo regnó... Hecho el libro postrimero día de diciembre, era de 1388 años. Nicolás González, escriban de los sus libros, lo escribí por su mandado». Vid. sobre este Domínguez Bordona, op. cit., vol. II, n. ${ }^{\circ} 1609$ y A. Domínguez RodríGuez, «La ilustración en los manuscritos medievales», pp. 332-335.

18 Tomo la cita de J. Camón Aznar, Pintura medieval española, Madrid, 1966, p. 177. Repito esta opinión en A. DoMínguez Rodríguez, «La ilustración en los manuscritos medievales» en Los manuscritos, de H. EscolaR (coord.), vol. I de la Historia ilustrada del libro español, ed. Fundación Germán Sánchez Ruipérez, Madrid, 1993.
} 


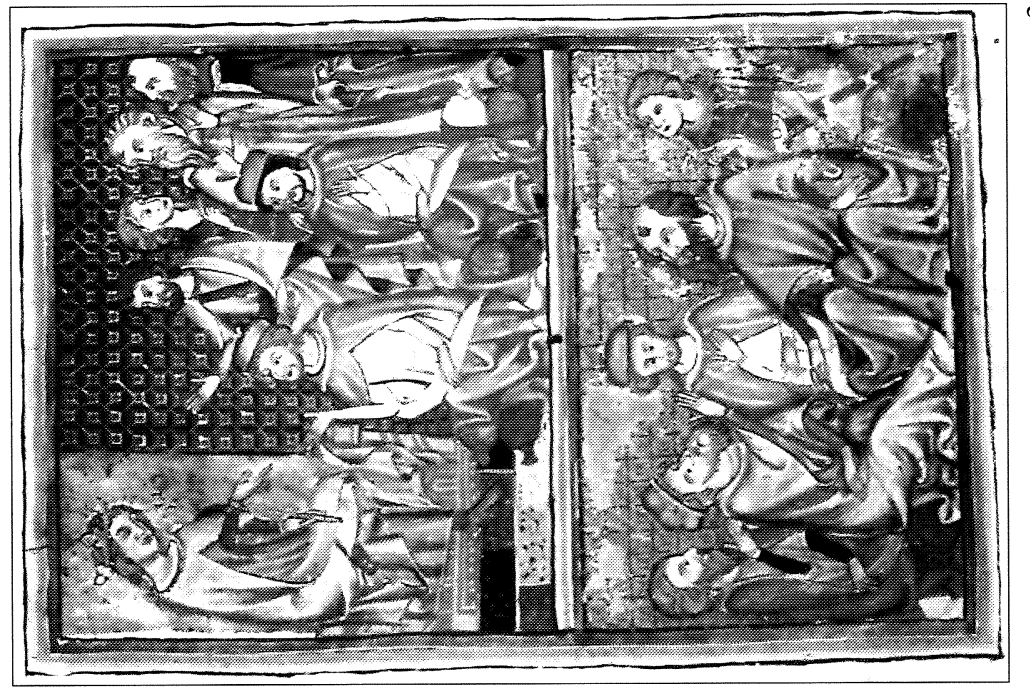

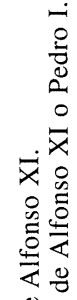

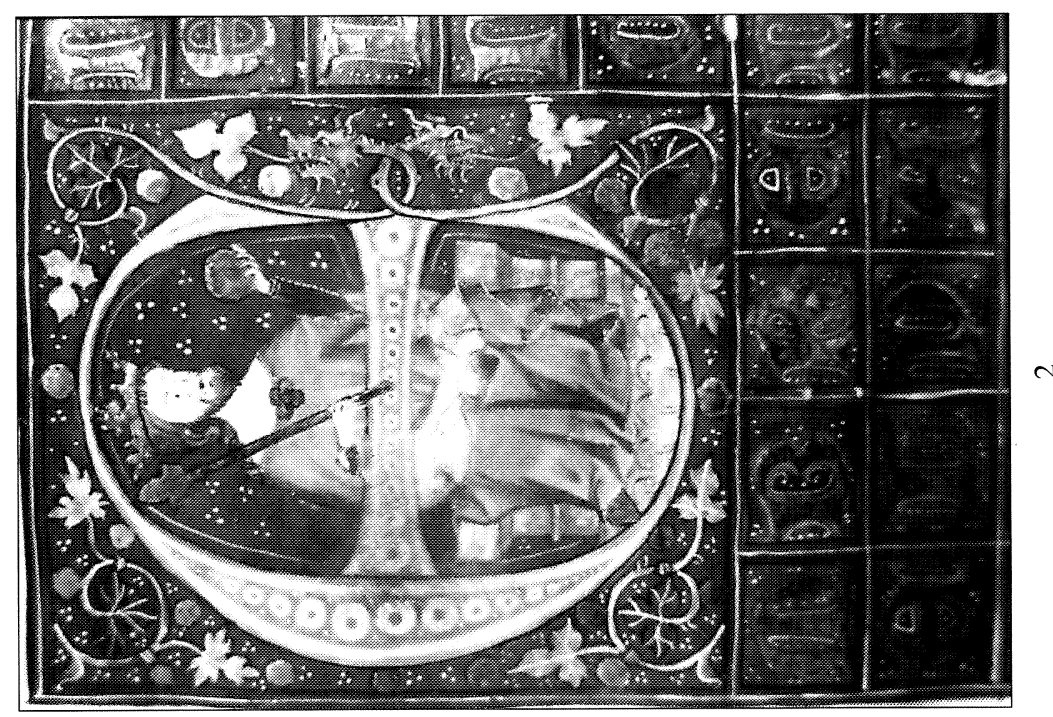

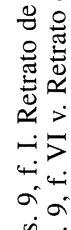

灾

首

苋完

을 $\frac{0}{2} \cdot \frac{\pi}{0}$

교요

工 핑

릉 음 웅

安里品

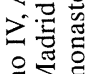

志过

융 웡

몽 웅을

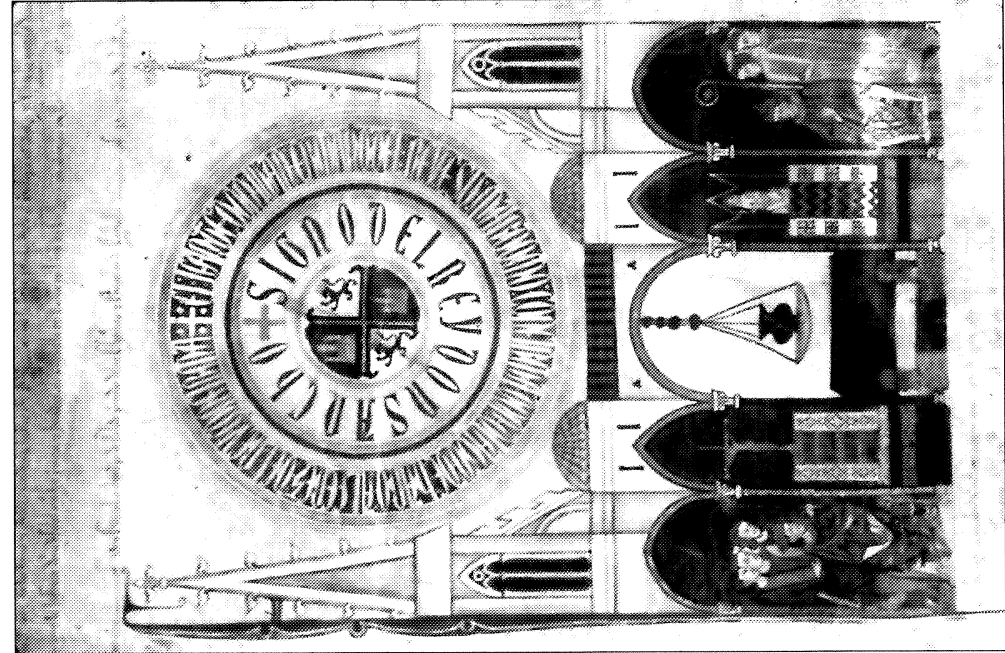

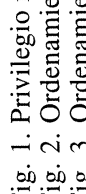

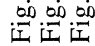


en la que se exhibe un retrato de Alfonso XI (fig. 2). Este retrato ha tenido mala suerte en las dos últimas exposiciones nacionales en las que ha participado (Toledo, 1984 y Sevilla, 1998) pues en ambas el personaje ha sido identificado con Alfonso X el Sabio, error imperdonable por los hechos históricos que se mencionan en ese mismo folio en donde se habla del rey como conquistador de Tarifa ${ }^{19}$ y por la iconografía del mismo. Pues aunque, como es bien sabido, las Partidas de Alfonso X el Sabio sólo alcanzarían vigencia legal en el Ordenamiento de Alcalá de su bisnieto Alfonso XI ${ }^{20}$, el retrato que encabeza el manuscrito se refiere a éste último monarca que es además el único mencionado en el encabezamiento del texto y cuya iconografía no responde en absoluto a la imagen del rey Sabio de la que hay ejemplos innumerables en sus manuscritos en los que, cuando se representa entronizado, aparece como sabio y no lleva, por lo tanto, el cetro y la poma que aparecen en manos del monarca representado en el ms. Res. 9 de la Biblioteca Nacional ${ }^{21}$.

El otro ejemplar iluminado del Ordenamiento de Alcalá, conservado en El Escorial (ms. Z. III. 9), es aún más lujoso y presenta dos miniaturas a plena página que se abren a modo de díptico (folios VIv. y VII). Se utilizan fondos de oro, siempre excepcionales en la miniatura gótica castellana, y en otros folios aparece una decoración vegetal iluminada con gran riqueza. Este manuscrito parece haber sido promovido por Pedro I, que continuó las empresas pictóricas de su padre ya que también la Crónica Troyana se sitúa en el ámbito, no bien delimitado, de ambos monarcas. No sabría en este momento identificar al soberano entronizado que preside la miniatura del folio VIv., acompañado por un grupo de cortesanos y funcionarios, que también aparecen en la parte inferior del folio (fig. 3). Estos últimos personajes, en pie y sentados, llenan los dos compartimentos del folio VII.

Las iluminaciones de estas dos versiones del Ordenamiento de Alcalá se apartan por completo de los patrones estéticos de la miniatura de Alfonso el Sabio, prolongada por Sancho IV, y manifiestan la plenitud de un estilo gótico lineal, derivado de modelos franceses o ingleses, que debe ser estudiado con mayor precisión.

En el Instituto Valencia de don Juan de Madrid se guarda un Privilegio de Enrique III (A. 9. 6. ), dado en Valladolid a 11 de septiembre de 1406, por el cual se confirma a Sancho Sánchez de Rojas, obispo de Palencia, un albalá anterior. En el ductus de la magnífica letra capital E, con la que se encabeza el manuscrito, se pintaron, en una disposición muy ornamental y decorativa, los retratos del monarca y del obispo, esgrimiendo éste último una filacteria. En la parte superior de la letra, con un claro sentido jerárquico, aparece la cabeza del rey, sobre un fondo de oro, llevando como único distintivo regio la corona (fig. 4). Gregorio de Andrés, que dió a conocer este documento, aprecia rasgos naturalistas en el rostro de este personaje que relaciona con la semblanza del monarca conocida por textos de la época ${ }^{22}$. Los estudios artísticos nos enseñan, sin embargo, que durante la Edad Media, en general y salvo excepciones

\footnotetext{
19 Vid. Alfonso X. Toledo. 1984, Madrid, 1984, p. 158 y fig. 116; A. Domínguez Rodríguez, «Errores en la exposición del séptimo centenario de la exposición de Alfonso X el Sabio», El País, jueves 27 de diciembre de 1984; la respuesta a esta crítica, también en El País y firmada por Javier Faci, comisario de la exposición de Toledo, argumentaba que en $M a$ nuscritos con pinturas de Domínguez Bordona (vol. I, $\mathrm{n}^{\circ} 818$ ) se atribuye el retrato a este rey. El error se repite en Metropolis Totius Hispaniae. 750 aniversario de la incorporación de Sevilla a la Corona castellana, exposición en el Alcázar de Sevilla comisariada por Alfredo J. Morales, Sevilla, 1998, n. ${ }^{\circ}$ 52, pp. 284-85.

20 Vid. M. González Jiménez, «Alfonso X, rey de Castilla y León (1252-1284)» en J. Montoya Martínez y A. Domínguez Rodríguez, El Scriptorium alfonsí: de los libros de Astrología a las Cantigas de Santa María, ed. Complutense, Madrid, 1999, p. 8, y J. SÁNChez ArCilla, «La obra legislativa de Alfonso X el Sabio. Historia de una polémica», en J. Montoya Martínez y A. Domínguez Rodríguez, ibidem, pp. 17-81.

21 Vid. A. Domínguez Rodríguez, «Retratos de Alfonso X en sus manuscritos», op. cit. supra., en donde resumo otros estudios anteriores míos sobre retratos del rey Sabio y establezco las coordenadas para un futuro estudio interdisciplinar que quiero emprender sobre el tema con la colaboración de otros especialistas.

${ }^{22}$ Vid. G. DE ANDrÉs, «Dos retratos auténticos. Enrique III de Castilla y Sancho de Rojas, arzobispo de Toledo» en Goya, 324-329 e ilustración en color de la portada con un detalle de la letra capital.
} 
muy documentadas como puedan ser los retratos de Carlos V el Sabio de Francia, representado con una nariz corvada ${ }^{23}$, el retrato no es fisionómico sino simbólico de la jerarquía social y el concepto del poder, en el caso de los gobernantes. Solamente en el Renacimiento, salvo contadas excepciones, se conquistará el naturalismo de los rostros. Esta ausencia de naturalismo indica una estética conceptual que no hay que anatematizar pues tampoco muchos de los retratos de la pintura del siglo xx son fisionómicos. El cambio del retrato conceptual al retrato fisionómico implica no sólo unas habilidades pictóricas (que los artistas de la Edad Moderna podían adquirir en las Academias) sino toda una concepción del universo y del lugar que ocupa el individuo en el mismo. El retrato de Enrique III que se guarda en el Instituto Valencia de Don Juan, aunque no posee valores fisionómicos, es una hermosa pintura de gran calidad y muy representativa del estilo gótico internacional.

En la exposición del Museo del Prado se muestran siete privilegios de Juan II, cinco de ellos con una decoración vegetal puramente ornamental, y uno con calidades claramente pictóricas, en el que se representa el retrato regio (Biblioteca de Francisco de Zabálburu, M 11-63). En este caso el monarca aparece con gran solemnidad, por la cátedra aparatosa en la que se sienta, la rica vestidura plateada y la enorme corona de oro. El rey sostiene una espada que se apoya muellemente en el suelo ${ }^{24}$ y que se exhibe como si fuera un símbolo de poder aunque otros ejemplos de rey con espada me hacen pensar en la ambigüedad de este objeto ${ }^{25}$. Existe algún otro privilegio de Juan II con decoración puramente ornamental, como uno que se guarda en la Cartuja de Miraflores y otro que, procedente de la misma cartuja, fue subastado en Sotheby en $1983^{26}$. Pero quiero destacar como pieza muy notable el privilegio otorgado por Juan II en el año 1424 y que se guarda en la Hispanic Society de Nueva York (ms. **HC 339/ $41)^{27}$. Si bien parte de su ornamentación es puramente vegetal esta se enriquece con los llamados «marginalia» $\mathrm{o}$ «drôleries», es decir temas burlescos en disposición märginal que aparecen con frecuencia en los códices iluminados (fig. 5). Dichos temas permiten en este caso establecer una relación con códices castellanos como la Biblia de Alba, iluminada en Toledo en época de Juan II aunque en el prólogo que documenta todo esto no se menciona la intervención del rey ${ }^{28}$. Además se ve, en lo alto de la letra capital, un dragoncillo, de cuya boca brotan unas hojas, que parece mostrar influencias de la miniatura parisina del gótico internacional que apenas ha dejado huella en los manuscritos iluminados castellanos ${ }^{29}$.

Conviene mencionar, por último, el retrato de Enrique IV, pintado en el folio inicial de un privilegio rodado concedido al marqués de Villena, al parecer en 1462 (Toledo, Sección Nobleza del Archivo Histórico Nacional), que es una obra maestra del iluminador Juan de Carrión,

\footnotetext{
23 Vid. C. Richter Shermann, The Portraits of Charles V of France (1338-1380), New York, 1969.

${ }^{24}$ E. Ruiz, pp. 121-22 en El documento pintado.

25 Vid. B. Palacios Martín, «Los símbolos de soberanía en la Edad Media española. El simbolismo de la espada» en VII centenario del infante Don Fernando de la Cerda, Madrid, 1976, pp. 273-296; A. Domínguez RodRíGuez, «Retratos de Alfonso X en sus manuscritos», op. cit., pp. 99-100.

26 Vid. J. Yarza, «Los Reyes Católicos y la miniatura» en M. C. LaCARra (ed.), Las artes en Aragón durante el reinado de Fernando el Católico (1479-1515), Zaragoza, 1993, p. 64.

27 Vid. Medieval Manuscript Treasures of the Hispanic Society of America, New York, 1993, fig. 1. Se trata de un breve folleto con hermosas ilustraciones en color. He de agradecer a Josefina Planas que me proporcionara un ejemplar del mismo.

${ }^{28}$ Esta relación entre el privilegio rodado de Nueva York y la Biblia de Alba ha sido mencionada por diversos autores. Vid.: Ch. Faulhaber, Medieval Manuscripts in the Library of the Hispanic Society of America, New York, 1993, II, 439440; J. Planas, «El manuscrito de Paris. Las miniaturas» en El Libro del Caballero Cifar, volumen complementario de la ed. facsímil, ed. Moleiro, Barcelona, 1996, p. 139; A. Domínguez Rodríguez, «La miniatura» en A. de la MorenA (coord.), Castilla-La Mancha en La España gótica, vol. 12, ed. Encuentro, Madrid, 1997, p. 81; A. Domínguez RodríGuez, «Sobre Juan de Carrión y su círculo. Un documento de pago en la catedral de Segovia y nuevas atribuciones» en Goya 274 (2000) pp. 17-26.

${ }^{29}$ Vid. A. Domínguez Rodríguez, «Sobre Juan de Carrión y su círculo. . . », op. cit. , p. 21.
} 


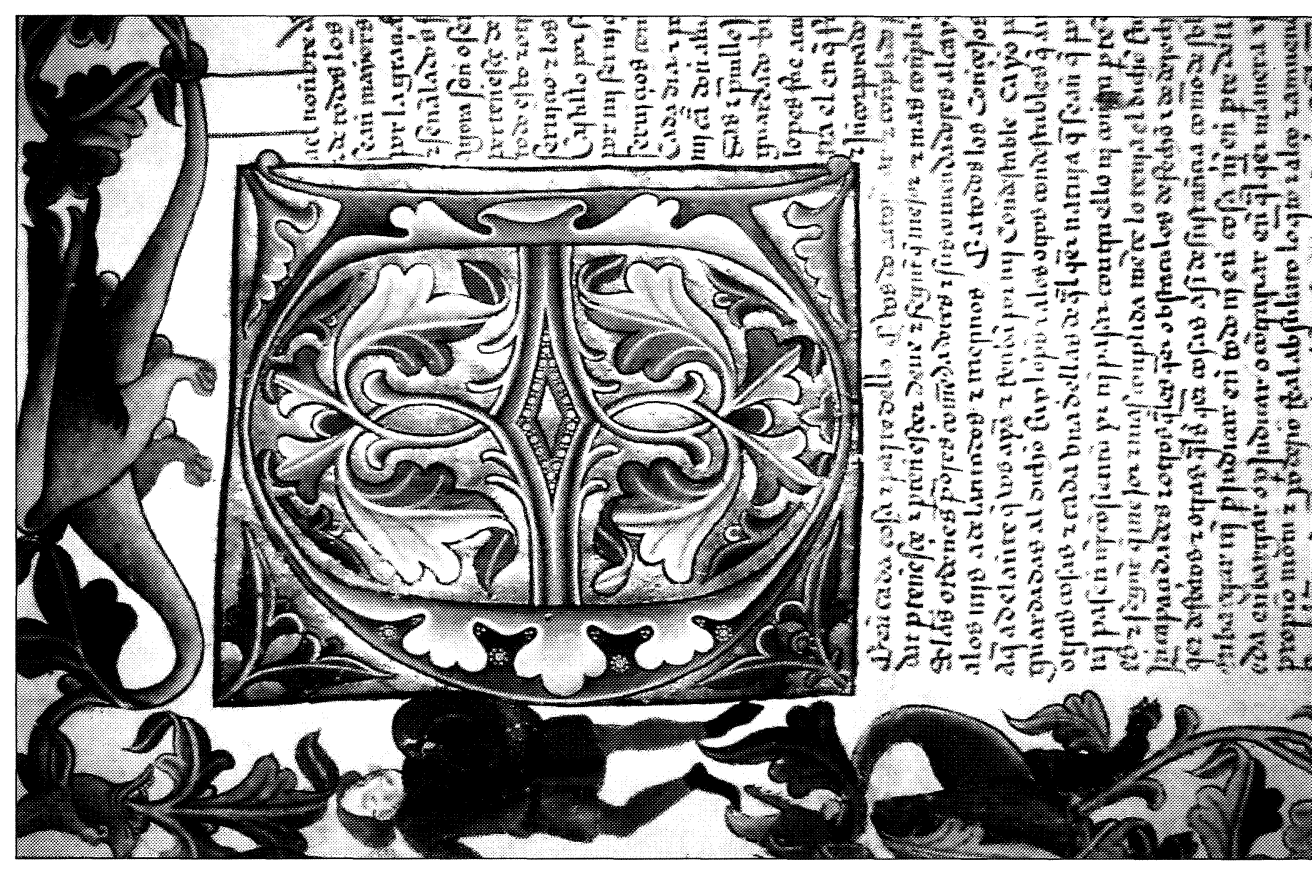

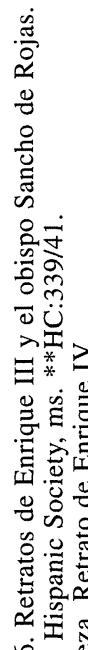

n
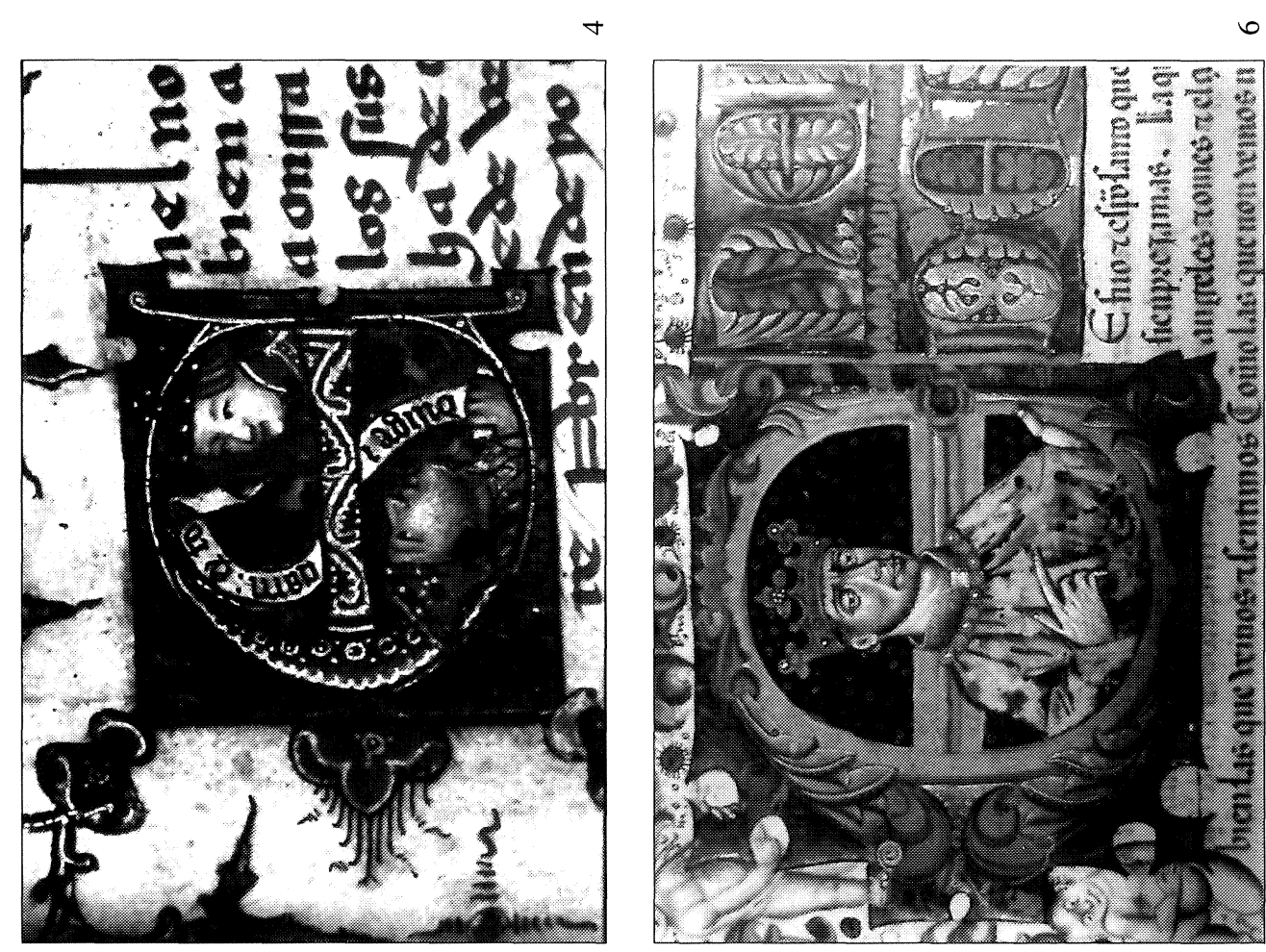

6

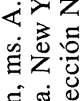

สี ฐี

ธิํํㅇํำ

음

娄这

可

㤩起

田这

罒然之

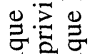

章㐘

ㅇํㅇํํㅇ 웅

옹 월 $\%$

늘

运

$+\sin 6$

完它这 
a quien ha sido atribuído convincentemente por Lynnette Bosch (fig. 6). La obra aparece en la exposición pero conociendo la pintura de ese artista creo que no se puede afirmar que este retrato constituya un reflejo de los rasgos fisionómicos del rey ${ }^{30}$ pues estos se confunden con los de otros individuos pintados por el mismo miniaturista, todos ellos con personalidad similar y muy acusada. Alix Saulnier ha definido a los personajes masculinos creados por Juan de Carrión diciendo que «... tienen con frecuencia un rostro atormentado marcado por un pliegue entre las dos cejas». Este es el tipo de rostro del Enrique IV expuesto en el Prado pero también el del Abraham de una Biblia romanceada escurialense y de diversos personajes de un Libro de Horas, en Berlín y Londres, que pudo haber sido realizado, en mi opinión, para este monarca castellano ${ }^{31}$.

No voy a añadir ningún ejemplo a los documentos pintados expuestos en el Prado de la época de los Reyes Católicos y Juana la Loca pero creo que deberían haber sido analizados también desde el punto de vista de la iluminación y dentro de la dicotomía que se observa en la miniatura castellana de la época. Por un lado existen obras espléndidamente iluminadas por miniaturistas flamencos, entre las cuales se encuentran el famoso Breviario de Isabel la Católica de la British Library y el Libro de Horas de Juana de Castilla, de la misma biblioteca ${ }^{32}$; y por otro obras hispanas, de un valor estético muy inferior, de las que podríamos citar los dos Breviarios de Isabel la Católica en el Escorial y en la Biblioteca Nacional, el Misal de Isabel la Católica de la Capilla Real de Granada, el Libro Blanco de la catedral de Sevilla, el Cancionero de Marcuello, por no citar un gran número de cantorales que presentan los escudos de los Reyes Católicos y otras obras menores ${ }^{33}$.

El profesor Erwin Palm, de la Universidad de Heidelberg me dijo en una ocasión: la Historia del Arte avanza con las exposiciones y los catálogos. Yo añadiría que también puede hacerlo con las críticas que suscitan algunas veces esas exposiciones, y catálogos.

Ana Domínguez Universidad Complutense

\footnotetext{
${ }^{30}$ E. Ruiz, op. cit., p. 130.

31 A. Domínguez Rodríguez, «Sobre Juan de Carrión y su círculo. . . ». En este articulo doy la fecha de 1463 para este privilegio rodado con el retrato de Enrique IV ya que cuando estuve en el Archivo de la Nobleza de Toledo, en noviembre de 1999, para estudiar este documento no me lo quisieron mostrar pues se encontraba expuesto en una vitrina. Pude ver únicamente un microfilm de poca calidad por lo que, aunque en mi artículo doy la fecha de 1463 para este documento (Elisa Ruiz habla de 1462) espero poder contrastar este dato con el original en otra ocasión. Para los estudios de Bosch y SAULNIER véase mi estudio arriba citado en el que resumo la lenta y esforzada recreación, y también recuperación, de la personalidad artística de Juan de Carrión por diversas generaciones de historiadores del arte desde Manuel Gómez Moreno hasta nuestros días.

32 En T. KREN, Renaissance Painting in Manuscripts (Treasures from the British Library), New York, 1983, se estudian ambos manuscritos. Véase también P. M. DE WINTER en «A Book of Hours of Queen Isabel la Católica» en Bulletin of Cleveland Museum of Art, diciembre de 1981, pp. 342-428. Ninguno de estos manuscritos se citan en Reyes y Mecenas. Los Reyes Católicos, Maximiliano I y los inicios de la casa de Austria en España, Madrid, 1992.

33 Vid. J. YARZA LuACES, «Los Reyes Católicos y la miniatura» en Las artes en Aragón durante el reinado de Fernando el Católico, de M. C. LaCarra (coord.), Zaragoza, 1993; idem, Los Reyes Católicos. Paisaje artístico de una monarquía, ed. Nerea, Madrid, 1992; A. Domínguez Rodríguez, «Las miniaturas del Cancionero de Marcuello» en El Rimado de la Conquista de Granada o Cancionero de Pedro Marcuello, vol. complementario de la ed. facsímil, Edilán, Madrid, 1995, pp. 399-447.
} 